EDITOR-IN-CHIEF

JOHN HICKNER, MD, MSC

Professor Emeritus

Michigan State University

Michigan State University

College of Human Medicine

\title{
Managing amidst COVID-19 (and everything else that ails us)
}

$\mathrm{T}$ his year, medical media has been dominated by reporting on the devastating COVID-19 pandemic. Many studies and analyses have shown that staying at home, social distancing, quarantining of close contacts, and wearing face masks and face shields are effective ways of preventing spread.

Although initially there were no known effective treatments for severe COVID-19 infection (other than oxygen and ventilator support), we now know that dexamethasone, ${ }^{1}$ remdesivir, ${ }^{2}$ and convalescent plasma ${ }^{3}$ are effective in lessening the severity of illness and perhaps preventing death. That said, we will continue to struggle with COVID-19 for the foreseeable future.

But other medical illnesses actually predominate in terms of morbidity and mortality, even during this pandemic. For example, although there has been an av-

\section{We must continue to tend to the other health care needs of our patients even as we deal with COVID-19.} erage of roughly 5600 COVID-19-related deaths per week for the past 4 months, ${ }^{4}$ there are, on average, more than 54,000 deaths per week in the United States from other causes. ${ }^{5}$ This means that we must continue to tend to the other health care needs of our patients even as we deal with COVID-19.

In that light, JFP continues to publish practical, evidence-based clinical reviews designed to keep family physicians and other primary health care clinicians up to date on a variety of topics. For instance, in this issue of $J F P$, we have articles on:

- Opioid prescribing (page 280). Although opioids have risks, they remain potent medications for relief from acute pain, as well as cancer-related pain and chronic pain not sufficiently treated with other medications. Mahvan et al provide expert advice on maximizing benefit and minimizing the risks of opioid prescribing.

- Secondary ischemic stroke prevention (page 272). For patients who have suffered a transient ischemic attack or minor stroke, a mainstay of prevention is antiplatelet therapy. Aspirin alone used to be the treatment of choice, but research has demonstrated the value of adding another antiplatelet agent. Helmer et al's thorough review reminds us that the antiplatelet drug of choice, in addition to aspirin, is clopidogrel, which should be used only for the first 30 days after the event because of an increased bleeding risk.

- Combatting Clostridioides difficile infection (page 293). CDI has been a difficult condition to treat, especially in high-risk patients. Zukauckas et al provide a comprehensive review of diagnosis and management. Vancomycin is now the drug of choice, and fecal transplant is highly effective in preventing recurrent CDI.

This diverse range of timely, practical, evidence-based guidance-in addition to coverage of COVID-19 and other rapidly emerging medical news stories-can all be 


\section{CHALLENGES TO IMPLEMENTATION}

Availability of PCR-based HPV assays may be an issue

HPV PCR assays may not be available at all laboratories, but signal amplification HPV tests have been shown to be inferior to PCR assays. Physicians will have to confirm with their laboratories whether PCR-based HPV assays are available.

\section{ACKNOWLEDGEMENT}

The PURLs Surveillance System was supported in part by Grant Number UL1RR024999 from the National Center for Research Resources, a Clinical Translational Science Award to the University of Chicago. The content is solely the responsibility of the authors and does not necessarily represent the official views of the National Center for Research Resources or the National Institutes of Health. Copyright @ 2020. The Family Physicians Inquiries Network. All rights reserved.

\section{References}

1. Arbyn M, Smith SB, Temin S, et al; Collaboration on Self-Sampling and HPV Testing. Detecting cervical precancer and reaching underscreened women by using HPV testing on self-samples: updated meta-analyses. BMJ. 2018;363:k4823.

2. National Cancer Institute Surveillance, Epidemiology, and End Results Program. Cancer stat facts: cervical cancer. www.seer. cancer.gov/statfacts/html/cervix.html. Accessed June 29, 2020.

3. Singh GK, Azuine RE, Siahpush M. Global inequalities in cervical cancer incidence and mortality are linked to deprivation, low socioeconomic status, and human development. Int J MCH AIDS 2012;1:17-30.

4. US Cancer Statistics Working Group. US Cancer Statistics Data Visualizations Tool, based on November 2018 submission data (1999-2016): US Department of Health and Human Services, Centers for Disease Control and Prevention and National Cancer Institute. June 2019. www.cdc.gov/cancer/dataviz. Accessed June 29, 2020.

5. MacLaughlin KL, Jacobson RM, Breitkopf CR, et al. Trends over time in Pap and Pap-HPV cotesting for cervical cancer screening. J Womens Health. 2019;28:244-249.

6. Freeman HP, Wingrove BK. Excess Cervical Cancer Mortality: A Marker for Low Access to Health Care in Poor Communities. NIH Pub. No. 05-5282. Rockville, MD: National Cancer Institute, Center to Reduce Cancer Health Disparities, May 2005. www. cancer.gov/about-nci/organization/crchd/about-healthdisparities/resources/excess-cervical-cancer-mortality.pdf. Accessed June 29, 2020.

7. FDA approves expanded use of HPV test. Infection Control Today March 31, 2003. www.infectioncontroltoday.com/guidelines/ fda-approves-expanded-use-hpv-test. Accessed June 29, 2020.

8. Ronco G, Dillner J, Elfström K, et al. Efficacy of HPV-based screening for prevention of invasive cervical cancer: follow-up of four European randomised controlled trials. Lancet. 2014;383: 524-532.

9. CDC. Cervical cancer screening guidelines for average-risk women. www.cdc.gov/cancer/cervical/pdf/guidelines.pdf. Accessed June 29, 2020.

10. Mao C, Kulasingam S, Whitham $\mathrm{H}$, et al. Clinician and patient acceptability of self-collected human papillomavirus testing for cervical cancer screening. J Womens Health. 2017;26:609-615.

11. Arbyn M, Verdoodt F, Snijders PI, et al. Accuracy of human papillomavirus testing on self-collected versus clinician-collected samples: a meta-analysis. Lancet Oncol. 2014;15:172-183.

12. Lazcano-Ponce E, Lorincz A, Cruz-Valdez A, et al. Self-collection of vaginal specimens for human papillomavirus testing in cervical cancer prevention (MARCH): a community-based randomised controlled trial. Lancet. 2011;378:1868-1873.
CONTINUED FROM PAGE 271

found on our Web site at www.mdedge.com/ familymedicine. We remain committed to supplying you with all of the information you need to provide your patients with the very best care - no matter what brings them in to see you.

JFP
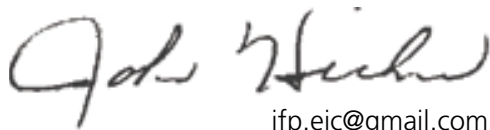

jfp.eic@gmail.com
References

1. Low-cost dexamethasone reduces death by up to one third in hospitalized patients with severe respiratory complications of COVID-19. Recovery: Randomised Evaluation of COVID-19 Therapy Web site June 16, 2020. www recoverytrial.net/ news/low-cost-dexamethasone-reduces-death-by-up-toone-third-in-hospitalised-patients-with-severe-respiratorycomplications-of-covid-19. Accessed July 1, 2020.

2. Beigel JH, Tomashek KM, Dodd LE, et al. Remdesivir for the treatment of Covid-19-preliminary report [published online ahead of print]. N Engl J Med. doi: 10.1056/NEJMoa2007764.
3. Li L, Zhang W, Hu Y, et. al. Effect of convalescent plasma therapy on time to clinical improvement in patients with severe and lifethreatening COVID-19: a randomized clinical trial [published online ahead of print]. JAMA. doi:10.1001/jama.2020. 10044.

4. Stokes EK, Zambrano LD, Anderson KN, et al. Coronavirus disease 2019 case surveillance-United States, January 22-May 30, 2020. MMWR Morb Mortal Wkly Rep. 2020;69:759-765.

5. Xu J, Murphy SL, Kochanek KD, et al. Mortality in the United States, 2018. NCHS Data Brief. 2020;1-8. 